\title{
The Significance of Using YouTube as an Academic Tool to Improve Students' Listening Skill in Libyan Universities
}

\author{
Ahmed Sanoussi Himeda Al Jawad ${ }^{1} 8$ (D) $\triangle$ and Asma Abdalrahman Mansour ${ }^{2}$ (iD \\ ${ }^{1}$ Assistant Professor, Department of English Language, Faculty of Arts \& Science Kufrah, Benghazi University, Libya \\ ${ }^{2}$ Assistant Lecturer, Department of English Language, Faculty of Arts \& Science Kufrah, Benghazi University, Libya \\ $\square$ Corresponding Author: Ahmed Sanoussi Himeda Al Jawad, E-mail: ahmed.jawad@uob.edu.ly
}

ARTICLE INFORMATION
Received: June 18, 2021
Accepted: July 20, 2021
Volume: 1
Issue: 1
DOI: $10.32996 /$ ijls.2021.1.1.5
KEYWORDS

YouTube, Listening Skill, EFL

Classroom, Libya Context.

\section{ABSTRACT}

This paper aims to investigate the significance of using YouTube in the EFL classroom to enhance students' listening skills in Libyan universities. In effect, YouTube is one of the important applications of information and communication technologies nowadays, which plays an essential role in creating a comfortable educational atmosphere that suits the learners' needs. To achieve the goal of this study, the authors relied on a descriptive method focusing on the quantitative framework. To this end, the authors were administered a questionnaire as a data collection tool for students. The questionnaire was designed for a sample of 60 students of second and third-year English language students at the Faculty of Arts and Science Kufrah, who were randomly selected. Through the questionnaire, data were collected, organized, and analyzed using statistical techniques like percentages. Based on the results of the paper, it can be concluded that students are very interested in improving their listening skills using YouTube videos. In turn, it promotes two significant factors: motivation and participation in the EFL classroom. At the end of the study, the authors stated a number of recommendations.

\section{Introduction}

Nowadays, new devices such as mobile phones, the internet, television, computers, and video games have become an integral part of students' lives. This new generation is completely different from their predecessors. They have grown up surrounded by new mechanisms and cannot imagine their life without them. They use them to learn as well as to socialize with others. This generation has been described by Marc Prensky as "Digital natives" (Prensky, 2001). He stated, "Our students have changed radically. Nowadays, students are no longer the people our educational system was designed to teach (ibid) ". Their brain process perceives new information differently than teachers expected or designed to teach it. Therefore, it becomes difficult for educators to find and develop innovative and effective ways to teach digital natives. There are many research studies on the benefit of using technology in teaching. Several proposals have been made for the education of this generation; YouTube is gradually becoming popular especially among young people.

Several researchers have discussed the impact of video-based materials on teaching English as a foreign language. However, the use of YouTube as an academic tool in teaching the English language is a new field of study and few posters have been published on the subject. In Libyan universities, videos are rarely used in teaching English as a foreign language. There is a lack of articles on the application of online media to language teaching. This may be indicated by the fact that some traditional teachers may find it unnecessary to apply video technology to achieve the goal of language teaching. Learners these days speak the language of the internet and technology that creates a gap between them and their teachers. Moreover, of all the English language skills, listening comprehension is often neglected and learners feel more depressed with the traditional audio method.

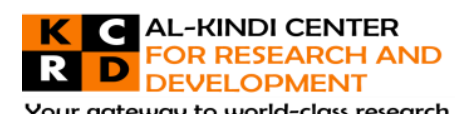

Your gateway to world-class research

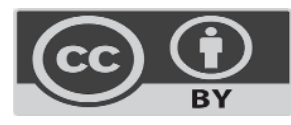

Published by Al-Kindi Center for Research and Development. Copyright (c) the author(s). This open access article is distributed under a Creative Commons Attribution (CC-BY) 4.0 license 


\subsection{Research Questions}

The questions of this study are as follows:

1. To what extent do EFL students develop listening skills through using YouTube?

2. What are the attitudes of EFL students towards learning listening skills through using YouTube?

\subsection{The Aims of the Study}

The aims of the study are:

1. To determine whether EFL students can learn listening skills through using YouTube.

2. To explore EFL students' attitudes towards learning listening skills through using YouTube.

\section{The Literature Review \\ 2.1 Definition of Terms \\ 2.1.1 YouTube}

Lee \& Liang, (2012) define YouTube as a video-sharing website that allows users from all over the world to watch videos posted by other users and upload videos of their own. It includes several kinds of videos such as educational, entertainment, political, historical, medical, and personal videos.

\subsubsection{Listening comprehension}

Although it is considered a receptive skill, it involves more than hearing; it is an active process. In this process, the listener must "discriminate between sounds, understand vocabulary and grammatical structures, interpret stress and intonation, retain what was gathered in all of the above, and interpret it within the immediate as well as the larger socio-cultural context of the utterance" (Bacon, 1989, p. 168). There are a number of definitions that many scholars have proposed regarding auditory comprehension.

One of the most significant skills in relevance to learning any language including our own mother tongue is listening. There are a number of definitions that many scholars have proposed regarding comprehension of listening comprehension. According to one of the earlier definitions given by Lado (1961), listening comprehension can be defined as "Recognition control of the signaling elements of the language in communication situations" (as cited in Suvorov, 2008, p. 5). Researchers claimed that listening is a process in which "Recognition of sounds, knowledge of lexicon, syntax, discourse markers, and the world, all interact with each other" (Bacon, 1989, p.544).

\subsection{The Effect of Videos on Listening Comprehension}

Using videos to facilitate learners' listening comprehension has been greatly discussed in the past two decades (Kusumarasdyati, 2004; Luo, 2004; Lin, 2009). Video materials improved students' listening comprehension skills because they are able to derive meaning from what they are watching and hearing thanks to the comprehensible input provided by the environment in which the video takes place. "Even without hearing the language spoken clues to meaning can be picked up from the vision alone" (Çakir, 2006, p. 68).

Lin (2009) investigated "the effects of visual aids and text types on listening comprehension. The results of the study showed a significant effect of input presentation modes on listening comprehension and their interaction with text types". Another study by Luo (2004) in which he examined "the influence of DVD films on students' listening comprehension. Nine films were incorporated into the class curriculum and used in the whole school year". The DVDs were the main materials of the course, supported by the designed activities. Instructional activities included story-telling, picture description, and open-ended questions for group discussion on topics retrieved from the films. The final results of the statistical analyses indicated that college freshmen's listening "did improve" through the instruction of using DVD films in a motivating learning environment with a lower level of anxiety after a whole school year. Another study by Kusumarasdyati, (2004) examined "the effect of using movie presentation on EFL learners' listening skills and imagination in Indonesia. He found that movies turn out to be an effective teaching technique in developing EFL learners' listening skills as well as stimulating their imagination and motivation". This paper recommended that foreign language pedagogy, especially for EFL learners would benefit from applying videos presentation with visual clues. It can be concluded that learners usually use their eyes as well as their ears, but their eyes are basic in learning.

\subsection{The Use of YouTube in Education}

Since the YouTube website is free, it makes it easy for both students and teachers to watch and upload videos. Teachers from all over the world have created their own YouTube channels and regularly upload various educational videos that numerous learners find it useful. Terantino (2011) stated, "YouTube offers fast and fun access to language and culture-based videos and instruction from all over the globe" (as cited in Alhamami, n.d., P. 3). It has potentials for online educational use as having been examined by

Page | 59 
many scholars such as (Burke \& Synder, 2008; Alimemaj 2010). YouTube is a rich source of culturally authentic materials that can motivate students to interact in an educational capacity with popular cultures through English language videos.

In short, YouTube videos has a fabulous prospective in English language classroom instruction. As one of the most used websites, the use of YouTube videos in Libyan EFL classrooms has enhanced students' English language skills and especially listening comprehension by opening up a new world for a more interesting and productive learning environment. Authentic YouTube videos assisted students to learn and practice the language as used by native English speakers. Furthermore, YouTube videos helped students develop their learning autonomy levels by encouraging them to continuously watch and explore English language videos in and out of the classroom.

\subsection{Suggestion for the Use of YouTube in the EFL Classroom}

According to Duffy $(2008$, p. 124) "YouTube is increasingly being used by educators as a pedagogic resource for everything from newsworthy events from around the world to "slice-of-life" videos used to teach students within an ESL (English as a Second Language) course". Therefore, this section will provide suggestions from educators and teachers from around the world who have used YouTube as a teaching tool in language teaching.

Although YouTube is very easy to use and has an open policy, sometimes the content can be inappropriate or too long to be shown in the classroom. So, there are some useful tools that teachers can use to either trim videos or remove some items like offensive comments (Beaudoin, 2013). These tools are View Pure and Tube Chop. The former tool is a website that can be used to filter out bad comments and other inappropriate content and the second software tool can be used to cut YouTube videos in which teachers can select the start and the stop point of a certain video (Beaudoin, 2013). Clark \&Mayer (2002) had recommended "some general guidelines for the appropriate use of YouTube. They believe that videos should be aligned with expected learning or performance outcome; reduce cognitive load; exclude superficial text or graphics; and be appropriate for target learner's learning literacy's" (as cited in Duffy 2008; p. 124).

Many EFL learners watch videos on YouTube but unfortunately few see it as an opportunity to develop their listening skills. If teachers of English as a foreign language can properly implement YouTube in the classroom, it will make learning English more creative and less traditional.

\subsection{Advantages and Disadvantages of Using YouTube Videos}

2.5.1 Advantages. Using videos in an EFL class can have many advantages for both teachers and learners. It is presented as follows: 1. Seeing language in use.

The first advantage of videos in the EFL classroom is that they help learners see and listen to language in its real context. To illustrate, Alimemaj (2010) argues that "videos provide an authentic language used by native speakers, as well as all language genres (songs, debates, talks, poems...)". This of course can be considered as a good way in order to learn a great deal of vocabulary which is important for developing one's oral fluency. In addition, Burt (1999) says that: "videos present real language that is not simplified and is spoken at a normal speed with a genuine accent" (p. 2). In this case, EFL learners will know how to react to the difficulties they encounter in speaking by getting used to hearing what native speakers use in their daily life.

\section{Cross-cultural awareness.}

In addition to seeing language in use, videos also develop EFL learners' cultural awareness of the target language. This can be confirmed by Stempleski (1987) who says that: "through videos, students can see how people in the target culture live, their values, customs, clothing, food and how people in that culture interact with one another" (p. 6). In this case, learners will gain background knowledge of the language studied which is very important in order to be fluent and in context when speaking. Additionally, videos will help them interpret native speakers' attitudes and reactions to different societal situations, a fact which has been underlined by Cakir (2006, cited in Shahani, Tahriri, \& Divsar, 2014). Chan and Herrero (n. d) in their turn point out that videos are considered vehicles that help learners develop an intercultural understanding (cited in Chowdhury, 2014). Accordingly, teachers can help their learners compare their native culture and the target language and then draw the similarities and differences about the topic orally.

\section{Raising discussion.}

Moreover, videos can be used as means for raising discussion in the EFL class. As stated by Stempleski (1987): "videos can work as a springboard for discussion" (cited in Watkins and Wilkins, 2011, p. 8). This is actually our main goal in the current study as we mean to enhance learners' oral fluency through discussions and debates related to the video they actually watched during the experimental procedure. As well, Burt (1999) says that "videos from YouTube help the students comment and ask questions about the video (cited in Al- zyoud \& Kabilan, 2012)". 


\section{Motivation.}

Moreover, watching videos can motivate learners to engage in different tasks. Yassaei (2012), states that "videos can be effective tools for breaking up the routine and incline the students to study the English language. In doing so, learners will become fluent speakers and autonomous ". As well, Joint Information Systems Committee (2002), reports that "videos are appealing materials that evoke students' emotional reactions and raise their motivation (cited in Hartsell \& Yuen, 2006) ". Therefore, videos in the EFL classroom are revealed by these researchers to create an enjoyable and motivating atmosphere that can help learners not only contribute to discussions within the class but can be the motive to attend EFL classes as the teaching environment becomes more striking and sounder.

\subsubsection{Disadvantages.}

In spite of the above-mentioned advantages, we admittedly agree that any technology tool is devoid of backsliding. The following, not all listed, are the most important items which can hinder EFL teachers as well as learners from using videos in an EFL classroom.

\section{Time constraints.}

According to Suvorov (2008) "using videos in EFL classroom is time-consuming. We almost share their point of view, because looking for videos that can be compelling and motivating for the learners is not so easy, and preparing adequate and appropriate in-class activities needs a lot of commitments from the teacher and EFL learners' ability to engage and satisfy such activities and inquisitiveness ".

\section{Limited software.}

Another disadvantage of videos as cited by Allan (1985 are you sure) is the limitation of the software. She asserts that "the problem with the new technology is that the hardware is always ahead of the software, and without the right materials it is difficult to exploit the resource to the full" (p. 47). Actually, if we don't have good software, we can't use the video effectively in the classroom; therefore, we strongly believe that the ground for such implementation must be available and well structured.

\section{Passive viewing.}

As well, Brophy (2007) states that "using videos can result to a passive learning process. We think that this can happen if the learners are not aware of the purpose of watching the video. Hence, it is up to the teacher to make his or her learners understand the fact that watching a video at home is not the same as in the classroom. In the classroom, video watching is purposeful as the EFL learners are directed and guided towards developing their ability to express themselves in English". Our view can be shared by Davies and Pearse (2000) who say that: "if learners are to participate willingly in class, they must understand what is expected from them" (p. 13). By doing so, they will be prepared both cognitively and linguistically.

\section{Research Methodology}

3.1 Method of the Study

In this study, the authors will proceed through a descriptive method, because it is convenient for this study, as it helps to describe and analyze the collected data. the data was collected and analyzed using percentages.

\subsection{Population and Sample of Study}

The population of the study is from English students who study the English Language for the academic year 2019/2020 at Kufrah Faculty of Arts and Science- Benghazi University. The authors chose a random sample from the population of study composed of (60) students for the survey study.

\subsection{Description of the Data Collection Tools}

In this study, the authors used a quantitative method as a data collection, and this design was gathered through a questionnaire which is considered as one of the appropriate and reliable tools that supply us with valid data. Furthermore, this study needs to be conducted via classroom observation to investigate the correlation between YouTube and listening skills to provide us with more validity to the finding, but due to many reasons especially possibilities and time which prevent us from using such means.

\subsection{Procedures for Analysing and Treating Data}

In this study, the authors have relied on charts, percentages, and descriptive statistics to analyze and interpret data.

\section{Data Analyses and discussions}

This one is mainly concerned with the analyses and discussions of the students' questionnaires.

\subsection{Presentation and interpretation of results: Students' Questionnaire}




\section{Discussion of the first question which states that:}

Q1. Do you use YouTube for Academic Purposes?

This question can be discussed in the following Chart 1.

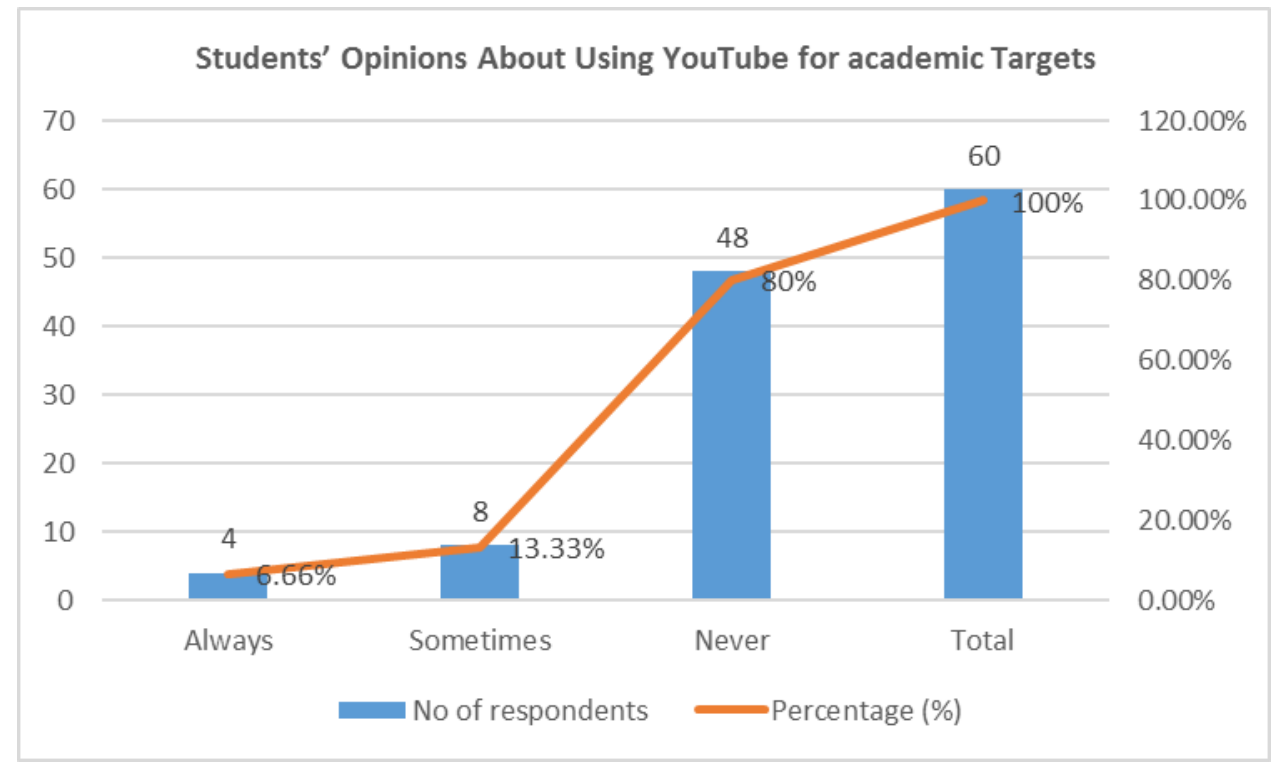

From the chart above, the authors intend to see how do EFL students use YouTube videos for academic purposes. From the results above, we can say that out of the whole sample $80 \%$ are never using it for academic purposes. While those who always use it for the same goal which is educational that represents $6.66 \%$. It aids students to satisfy their needs in their English language studies. In contrast with the previous results, $13.33 \%$ show that the participants sometimes use YouTube videos for the academic Targets.

Q2. Do your Teachers use an academic tool like YouTube in EFL Classroom? This question can be discussed in the following Chart 2.

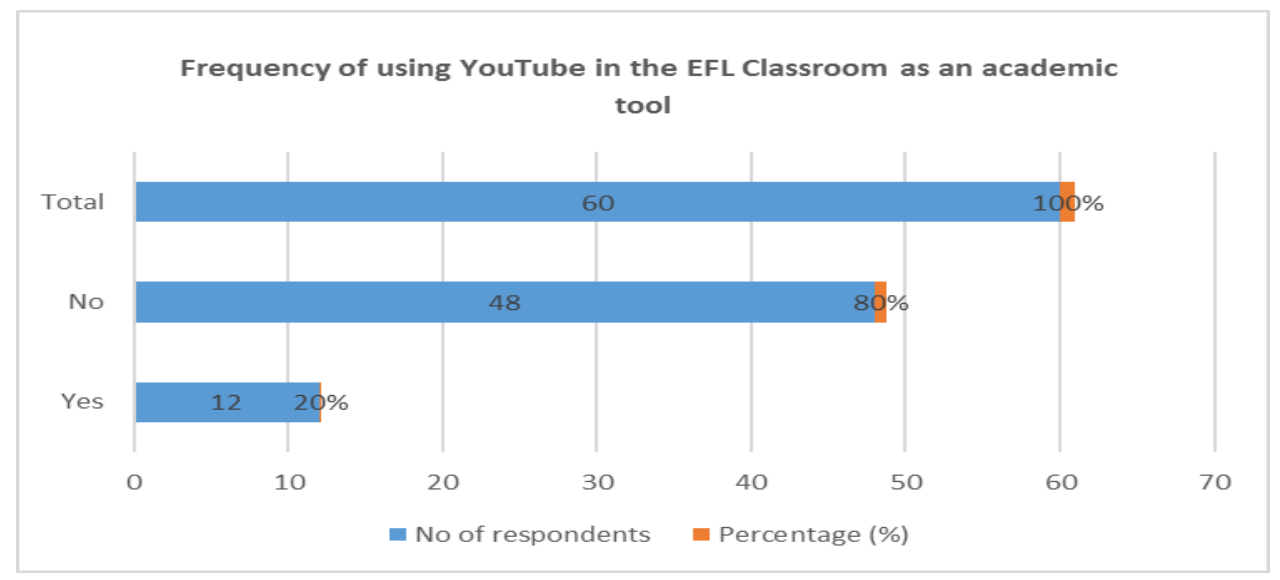

According to chart 2, which demonstrates the frequency of using YouTube in the EFL classroom as an academic tool, it is apparent from $80 \%$ which represents the option 'No' that the majority of the teachers did not incorporate YouTube as a supplementary tool within the classroom.

Whereas $20 \%$ of the participants claim the implementation of YouTube inside the classroom. We can deduce that there are teachers who do not utilize such materials while state 'No' for unknown reasons.

Q3. What is your point of view about incorporating YouTube as an academic tool in the Classroom?

This question can be discussed in the following Chart 3. 


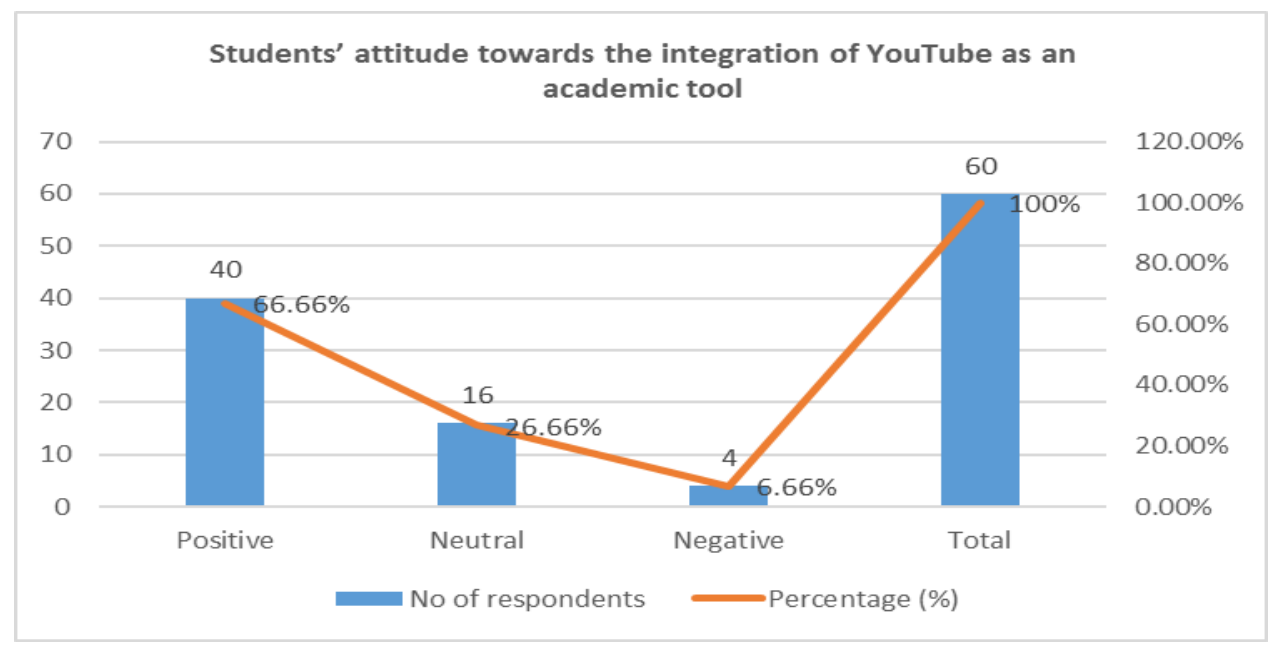

According to the results mentioned above, it is clear that more than half of respondents with $66.66 \%$ percentage have a positive opinion about the incorporation of YouTube inside the classroom. Whereas $26.66 \%$ of the participants are neutral with this view, they are neither positive nor negative.

In addition, $6.66 \%$ of them said they have a negative attitude about the integration of YouTube as a teaching aid. As a result, we realize that the majority of the students are extremely positive about this idea, probably because EFL learners as a digital generation need more authentic materials to match their needs.

Q4. Does YouTube raise your interest to develop your English listening skill?

This question can be discussed in the following Chart 4 .

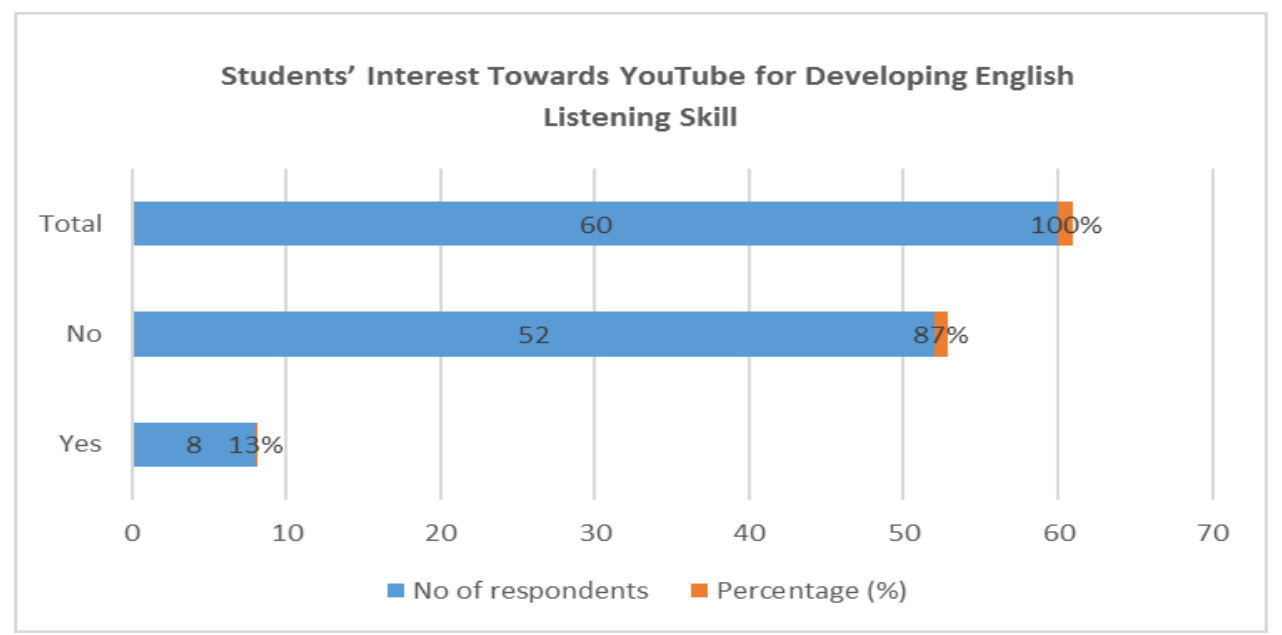

The majority of participants (87\%) considers that while they use YouTube in their interest for developing English listening skill is raised efficiently. Unlike $13 \%$ of the respondents who reported that YouTube did not bring up their interest to enhance their listening skills. Hence, from the previous results, we note that this technology material is very helpful in raising the interest of EFL students in order to boost their English listening skills.

While those who respond negatively to this statement think that these resources did not suit their interest and ability for increasing listening skill awareness.

Q5. In your opinion, using YouTube in the classroom lessons will be more interesting than the traditional method?

This question can be discussed in the following Chart 5 . 


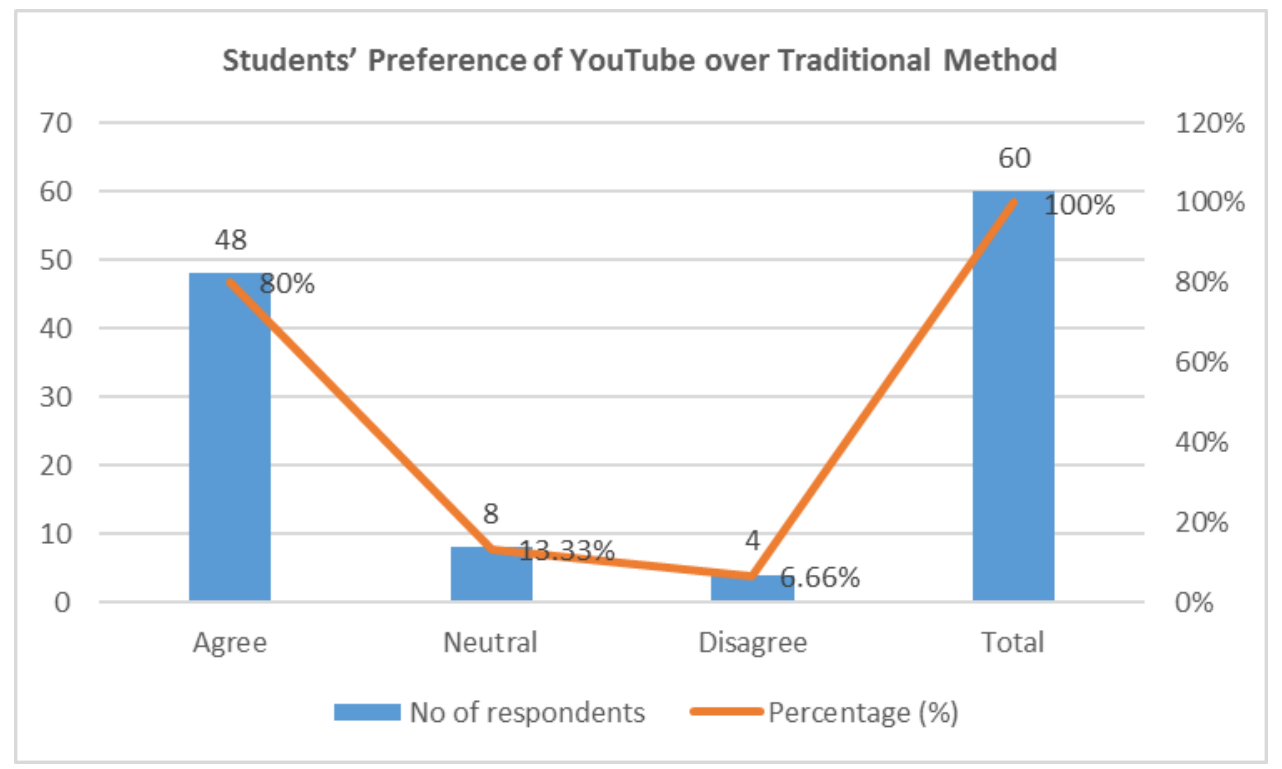

The above question seeks to investigate the students' attitude about using YouTube videos in the classroom lessons will be more interesting than the traditional method or not. As we can see from chart 5 that out of $80 \%$ of the students are agreeing that the classroom lessons will be more interesting with the use of YouTube videos. While $13.33 \%$ of the participants asserted that they are neutral between the use of both methods. Whereas, the rest findings results classified, $6.66 \%$ of the respondents who disagree.

To sum up, the participants who were neutral stated that both of the teaching methods have their advantages and disadvantages. Also, the education process needs mixed procedures such as YouTube which can reinforce the traditional way. In short, all based on the teacher's guidance.

Q6. What kind of YouTube contributed to improving your Learning of English?

This question can be discussed in the following Chart 6.

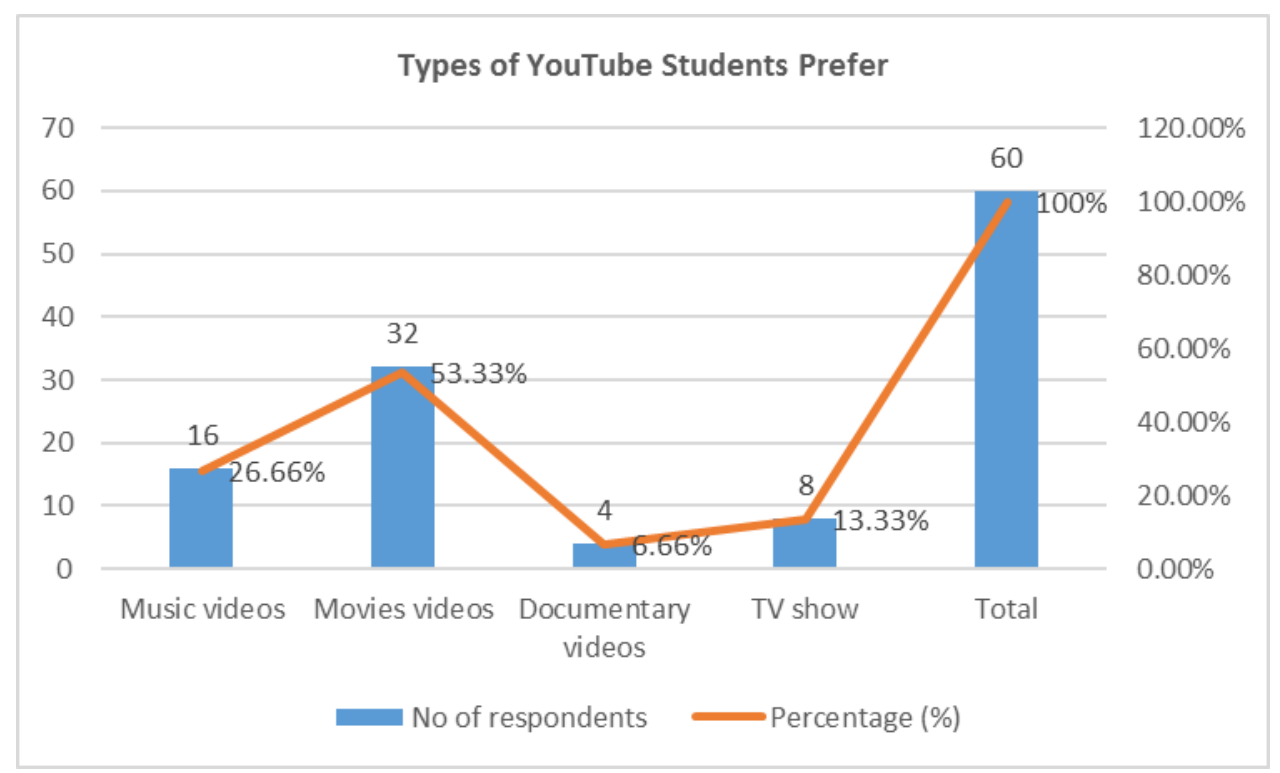

From the above question, we want to explore the most types of YouTube that students preferred and at the same time contributed to developing their English. However, as illustrated in chart 6 that more than half of the participants (53.33\%) prefer watching movies videos that in their opinions help them to improve their learning of the English language and $26.66 \%$ represent those who use music videos, whereas, $6.66 \%$ of them use the documentary videos as a way of practicing English. On the contrary, $13.33 \%$ of the learners indicated their preference towards TV shows. 
Q7. Does using YouTube in the classroom enhance students' motivation and participation? This question can be discussed in the following Chart 7.

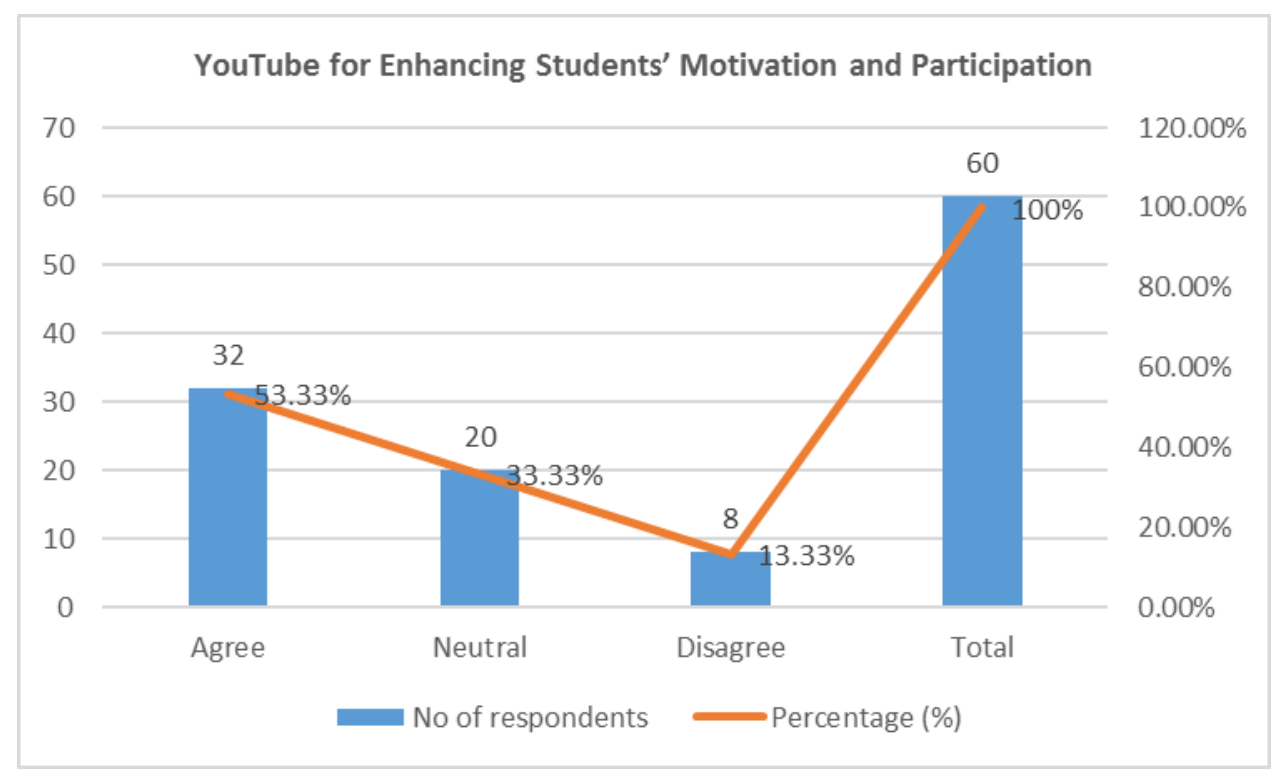

It is apparent from the survey results that the wide of the respondents with the percentage $53.33 \%$ agree that using YouTube videos in the classroom enhances students' motivation and participation.

While $33.33 \%$ of them show their neutral opinion about that statement. Otherwise, $13.33 \%$ goes to those who show their disagreement which they consider YouTube does not increase students' motivation and participation.

If you agree, Because:

Table 8: YouTube and the Classroom Environment This statement can be discussed in the following Chart 8.

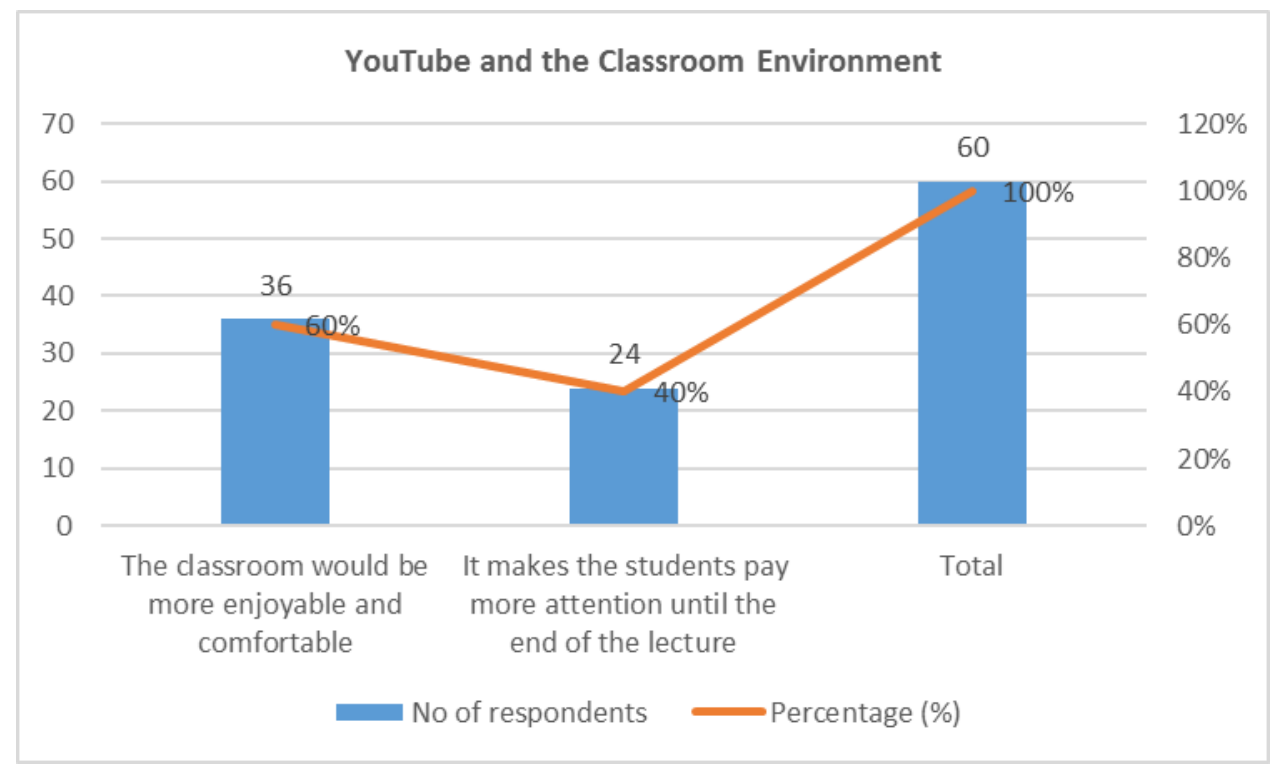

We can be remarkable from chart 8 above that the majority of participants (60\%) stated their considerable agreement with the statement which indicated that using YouTube make the students pay attention until the end of the lecture. Whereas, $40 \%$ of learners showed their agreement concerning the first statement that says that the classroom would be more enjoyable and comfortable. In fact, that both results lead us to the positive role of YouTube as an interesting teaching aid in the classroom, especially it deals with the psychological side of the learners which reduce the anxiety and enhance the motivation of the student. 
Q8. Do you think YouTube can simplify understanding the lecture content? This question can be discussed in the following Chart 9.

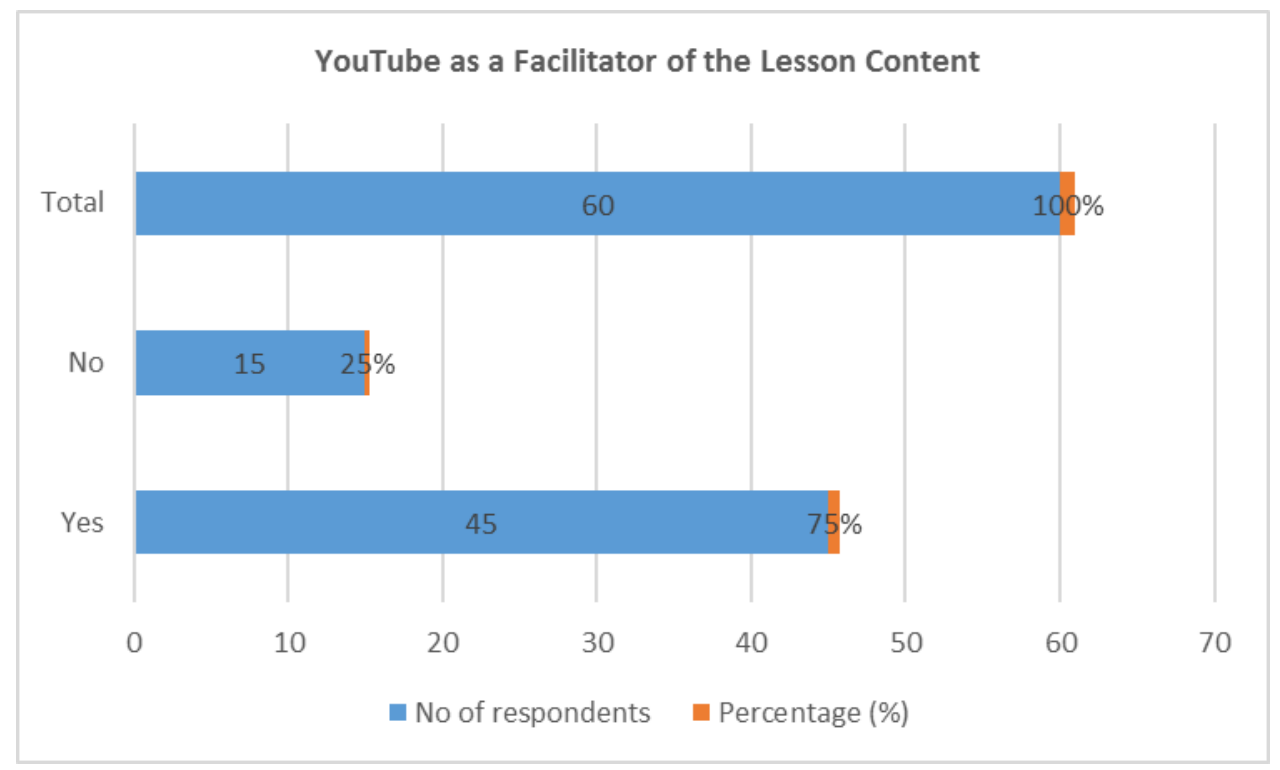

We observed that the overall percentage of the students who says 'Yes', that YouTube can simplify understanding the lecture content is $75 \%$ while $25 \%$ of the participants' response negatively towards this idea. The data findings prove that YouTube can be a facilitators tool that aids students to understand the lecture.

Q9. In Your Opinion, Listening Skill Is Important in Comparison with Other Modules of the English Language? This question can be discussed in the following Chart 10.

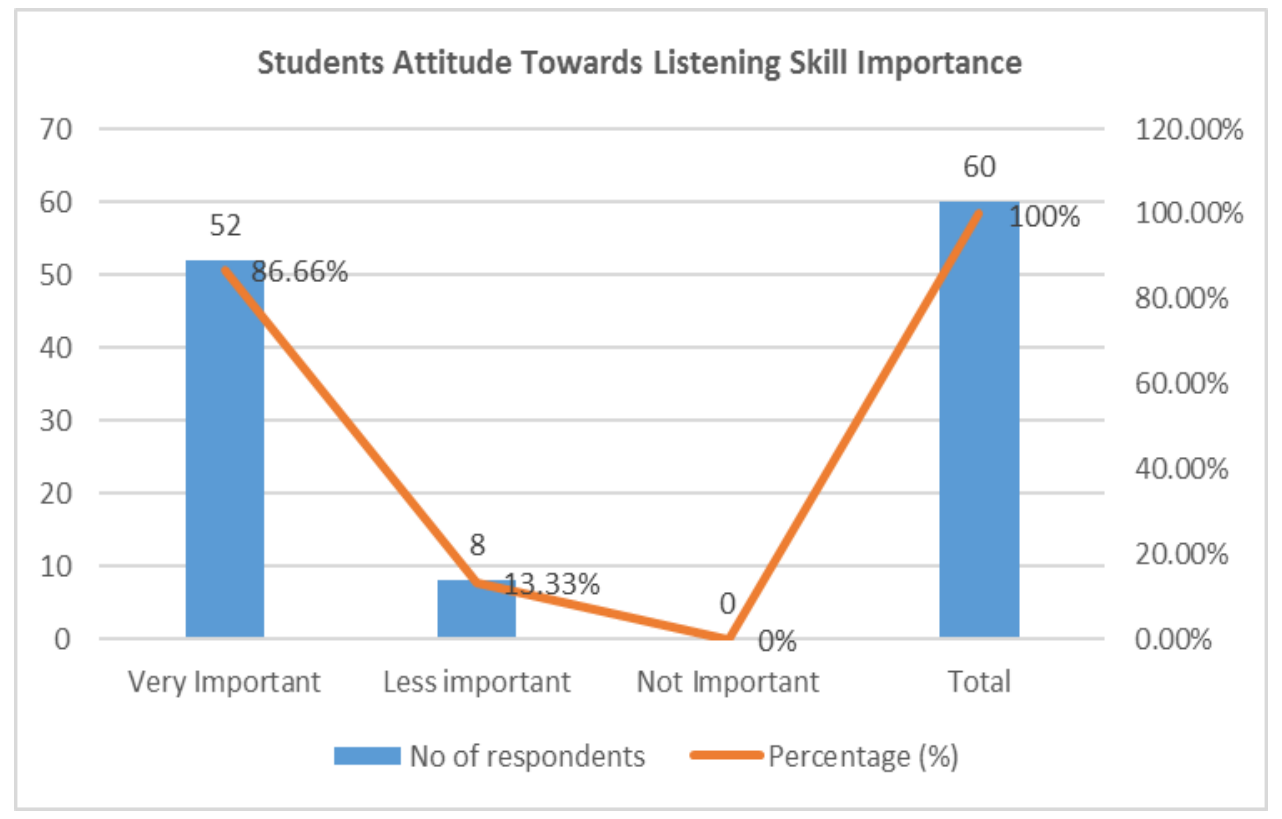

From the above question, we seek to see students' standpoints towards the importance of listening skill in the English language, especially listening skill which is not taught as separate modules like another subject of the language. However, the overall views of the participants with (86.66\%) indicate that listening skill is crucial in comparison with other modules of the English language. Yet, $13.33 \%$ of them claimed that listening skill is less important than other subjects. Whereas none of the learners says, that it is not important.

Hence, we emphasize the necessity of the listening skill in the target language and the EFL classroom, also, the EFL learners are very aware of that language aspect. 
Q10. What are the main reasons that prevent students to use their listening skills?

This question can be discussed in the following Chart 11.

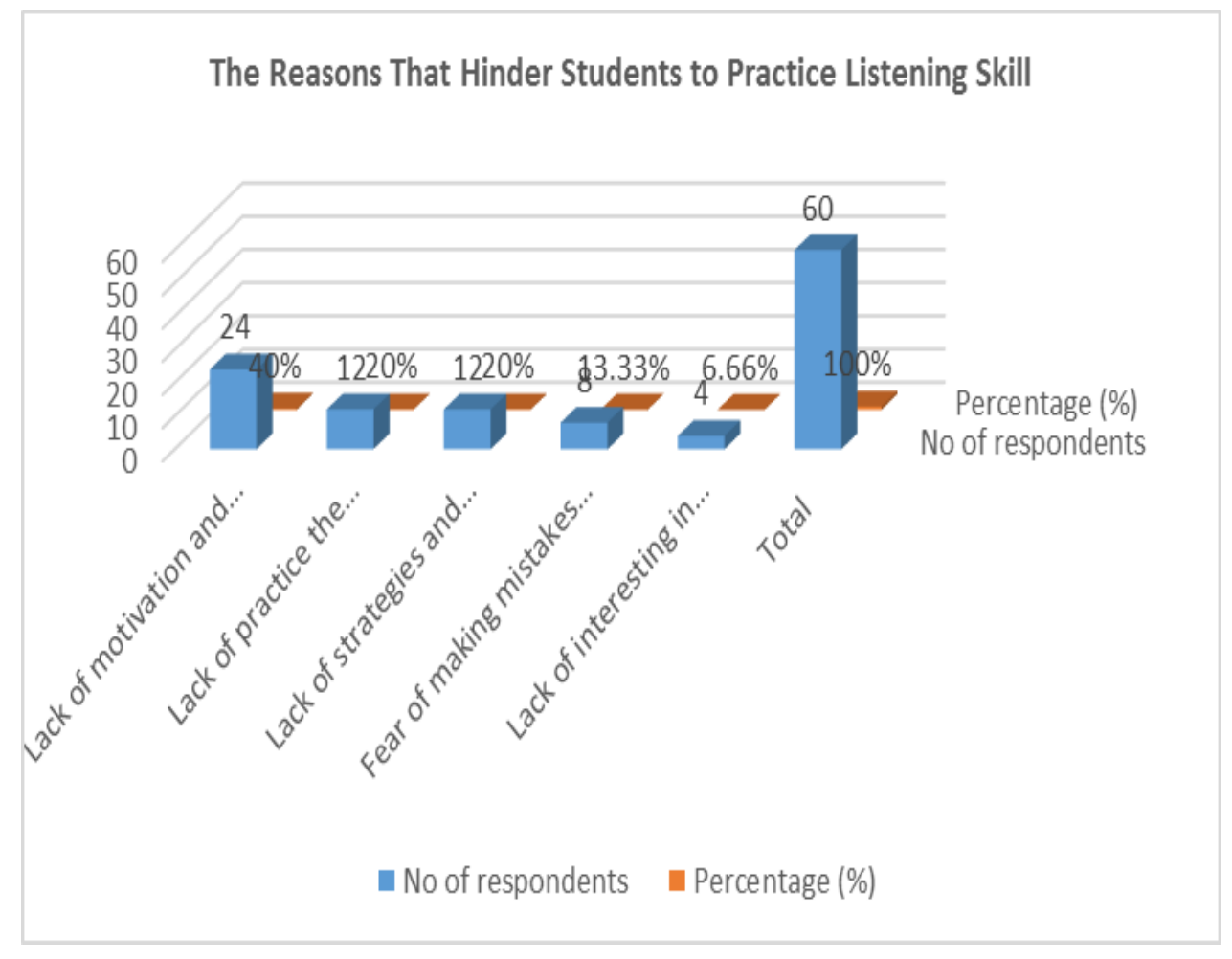

As it is shown in chart 11 above, $40 \%$ of the participants demonstrates that the major reasons that prevent students to using their listening skill inside the classroom are due to lack of motivation and interest to speak English. While 20\% represents those who stressed that lack of practice the meaning of the new words in a natural context and also the fear of making mistakes and feeling embarrassed when vocalizing the words are the most problems that hinder them to practice their active listening (20\% for each).

On the contrary, $13.33 \%$ of the respondents considered that the lack of strategies and techniques in learning listening skills is one of the most difficulties they encounter EFL students to using the listening skill aspect. Likewise, $6.66 \%$ of the participants who agreed with the last statement which represents the reason for the lack of interest in the current method of teaching (textbook, printed materials). As we can see the data finding reveals that the motivation factor is considered the foremost reason to involve listening and speaking any language because the more the teacher encourages the students and he promotes their motivation as much they being interesting to faster their listening learning.

Q11. Do you think that practicing English using YouTube regularly and repeatedly may help you acquire more listening skills? This question can be discussed in the following Chart 12. 


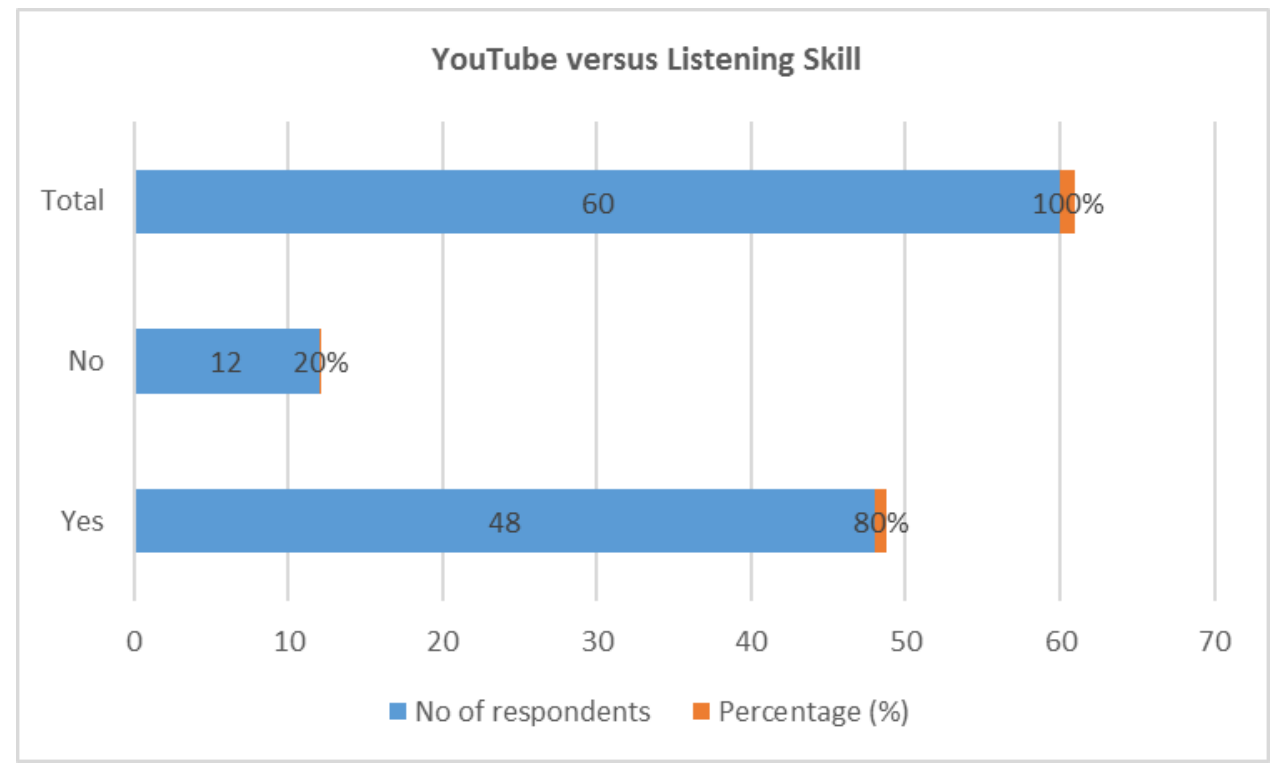

As it is presented in the data results, which shows that the vast majority of the participants (80\%) assumed that practicing English using videos on YouTube regularly and repeatedly help them to acquire more listening skills which they expressed a positive attitude. The other $20 \%$ of the learners did not find that the regular practice is beneficial for them, might be they have other ways to acquire listening skills.

However, the positive answer of the participants leads us to point out that EFL students have the desire to improve their listening skills because the more students practice the more they can learn to pronounce words in the right way and at the same time promote the burden of their listening skills.

Q13. To what extent, the listening to native speakers' videos can enhance your level of Listening Skills? This question can be discussed in the following Chart 13.

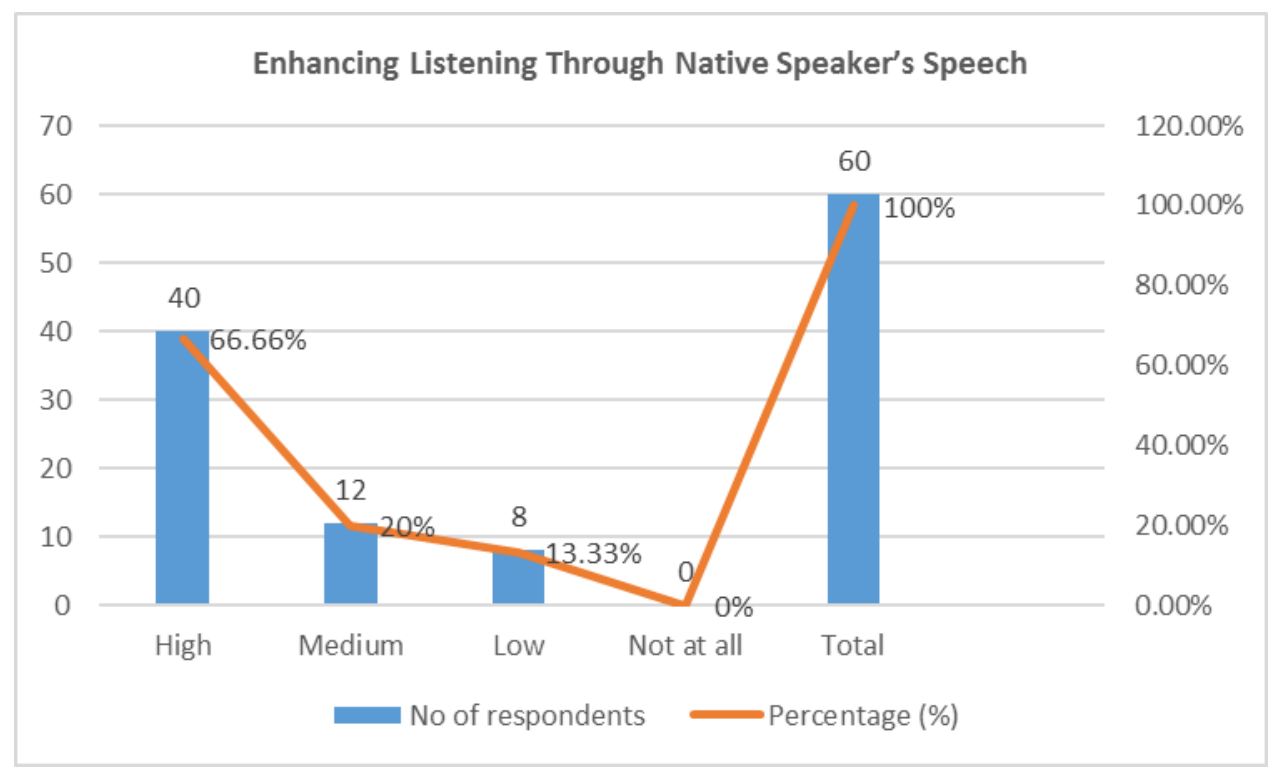

We can see from chart 13 that $66.66 \%$ of students with the "high" response asserted that listening to native speakers' videos develops their level of listening. While $20 \%$ consider the amount of developing vocabulary through listening to native speakers' videos as a medium. Yet, the other respondents choose the 'low' response, whereas two students with $13.33 \%$ percentage said that found the listening to videos of native speakers did not ameliorate their levels of listening maybe because they are not able to follow the quick speech on the video. 
From the results mentioned above, we can realize that listening to native speakers' videos assists students in progressing their level of listening which leads them to foster their English proficiency in general.

\subsection{Discussion of the Results}

Based on the data results obtained from the above analysis the authors claim that:

- $\quad$ EFL students demonstrate their positive attitude towards learning listening skills through using YouTube videos in the EFL classroom. They indicate that the lectures will be more interesting than the traditional method. On the contrary, YouTube videos simplify for students the information they need and make the EFL classroom an active context rather than having instruction in an indeclinable method. Although, the students asserted that YouTube videos can play as a facilitator tool to simplify understanding the lesson content in general and raise their interest to develop listening skills in particular. On the other hand, most of the students supposed that not all teachers use such tools for delivering lectures and even do so, they sometimes combine it within the EFL classroom lesson not always.

- In terms of motivation, most EFL students show their satisfaction towards using YouTube videos as a motivational means, and they admitted that the use of this resource improves their participation and curiosity inside the EFL classroom. Moreover, EFL students indicated that videos make them pay more attention until the end of the lesson and give them chance to learn in a comfortable atmosphere.

- The majority of EFL students with a percentage of $90 \%$ claimed that listening is important in comparison with other modules of the English language. As they demonstrated that listening enables EFL students to go forward with the language, promote their critical thinking, make them get fluency and feel at ease when communicating with other people.

- Furthermore, as it is clarified in the data results that the lack of motivation and interest to speak English is the main reason that prevents students to practice their listening. Besides, the EFL students are afraid of making mistakes and feeling embarrassed when pronouncing the words. Moreover, most of the participants agreed that practicing English using videos on YouTube regularly and repeatedly help them to acquire listening, and this through the useful listening to native speakers' speech which assist them to exploited their right pronunciation and provided them with new words to use it in their verbal and non-verbal messages. Otherwise, $60 \%$ of the EFL students declare the necessary combination of both verbal and visual techniques for practice listening in the classroom. Probably to enrich the classroom with plentiful strategies that support the development of learning listening and increase students' English language proficiency.

\section{Recommendations}

According to the above-mentioned results, the authors recommend the following:

$>$ Teachers should consider the different learning styles and assist their students in reflecting their experience with English videos to communicate their ideas and attitudes, and to raise their sense of interest in the language.

$>$ Teachers should provide EFL learners with the opportunity to acquire more listening skills and be comfortable, teachers attempt to create cognitive learning by engaging the students in learning using interesting video activities.

$>$ EFL teachers should be aware that the use of technological resources requires training in order to meet curriculum goals. To this end, teachers should be involved in the technological training program.

$>$ EFL teachers should establish a good teacher-learner partnership because effective classroom discipline relies on teachers' competence to create a good relationship with their students.

$>$ Both EFL learners and teachers should interact with a pedagogical channel as online courses as they do in any educational group in social media

$>$ EFL teachers should provide learners with CD of various English situations explained by native speakers to increase their knowledge in a natural context to contribute to their learning needs.

$>$ EFL students should practice outside the classroom is highly recommended for learning listening skills in order to make progress in improving their English level. Because the more learners practice, the more they can acquire listening and correct pronunciation in order to get experience so as to perform efficiently and effectively.

\section{Conclusion}

In this paper, the authors used one tool, the questionnaire, which was helping to check students' perceptions of using YouTube as an academic tool. From what is discussed through the results. The authors can confirm two main things: the positive attitude of EFL learners towards the use of YouTube in improving students' listening skills. Therefore, this material gives learners an opportunity to become familiar with new words and increase their knowledge of listening skills. Also, learners have strongly advocated regarding the adaptation of such new forms of technology as a teaching tool in the classroom that aids and facilitates English language learning, develops students' listening skills, and changes the classroom setting.

\section{References}


[1] Alhamami, M. (2013). Observation of YouTube Language Learning Videos. Teaching English with Technology, 13(3), 3-17. Retrieved on October, 2014, from http://www.tewtjournal.org.

[2] Allan, M. (1985). Teaching English with Video. Essex: Longman.

[3] Alimemaj, Z. (2010, May). YouTube Language Learning and Teaching Techniques. The Magazine of Global English Speaking Higher Education, 2 (3), 10-12. Panethnic Limited. Retrieved on January, 2015, from http://www.anglohigher.com/magazines/download_pages/61.

[4] Al-zyoud, K., \& Kabilan, M. (2012, August 31). The use of YouTube in Teaching English Literature: The Case of Al-majma'ah Community College. International Journal of Linguistics, 4 (4), 525-551. Doi:10.5296/ijl.v4i42930.

[5] Bacon, S. (1989), Listening for Real in the Foreign-Language Classroom. Foreign Language Annals, 22: 543-550.

[6] Beaudoin, P. (2013). iTunes, YouTube and Me: Augmented Your Classroom with Web-Based Media. In T. Bastiaens \& G. Marks (Eds.), Proceedings of World Conference on E-Learning in Corporate, Government, Healthcare, and Higher Education 2013 (pp. 45-53). Chesapeake, VA: AACE. Retrieved from http://www.editlib.org/p/114796/

[7] Brophy, J. (2007). Using Video in Teacher Education: Advances in Research on Teaching, vol.10. New York: Emerald Group Publishing Limited.

[8] Burke, S., \& Snyder, S. (2008). YouTube: An Innovative Learning Resource for College Health Education Courses. International Electronic Journal of Health Education, 11(1), 39-46.

[9] Burt, M. (1999). Using Videos with Adult English Language Learners. National Clearinghouse for ESL Literacy Education Washington DC. NO: ED 445551, 1-11. Retrieved on October, 2014, from http:// files.eri.ed.gov/fulltext/ED434539.pdf

[10] ÇAKIR, I. (2006). The Use Of Video As An Audio-Visual Material In Foreign Language Teaching Classroom. The Turkish Online Journal of Educational Technology, 5(4), 67-72.

[11] Chowdhury, T. (2014, May). Audiovisual Material in Language Teaching: Learners'Perspective. (Master's Thesis, BRAK University, Dhaka, Bangladesh). Retrieved onDecember, 2014, from http://dspace.bracu.ac.bd/handle/10361/3324

[12] Clark, R., \& Mayer, R. (2002). E-Learning and The Science of Instruction: Proven Guidelines for Consumers and Designers of Multimedia Learning. (3 ed., p. 528). San Francisco: Jossey-Bass Pfeiffer.

[13] Davies, P., \& Pearse, E. (2000). Success in English Teaching. Oxford: Oxford University Press.

[14] Duffy, P. (2008). Engaging the Youtube Google-eyed Generation: Strategies for Using Web 2.0 in Teaching and Learning. Electronic Journal of e-Learning, 6(2), 119-129.

[15] Hartsell, T., \&Yuen, S. (2006). Video Streaming in Online Learning. AACE Journal, 14 (1), 31-43. Retrieved on January, 2015, from http://www.editlib.org/p/6152/article_6152.pdf

[16] Kusumarasdyati N. (2004, 7). Listening, Viewing and Imagination: Movies in EFL Classes. 2nd International Conference on Imagination and Education, Vancouver, Canada. Retrieved

fromhttp://www.google.com.sa/url?url=http://www.ierg.net/confs/2004/Proceedings/Kusumarasdyati.pdf\&rct=j\&frm=1\&q=\&esrc=s\&sa=U \&ei=-g0bVLnrL8S_PNb6gJgD\&ved=0CBcQFjAA\&usg=AFQjCNELpMpZgXrS808XA52KfU4kOhzCpQ

[17] Lado, R. (1961). Language Testing: The Construction and Use of Foreign Language Tests. London: Longman.

[18] Lee, J. Y., \& Liang, C. J. (2012). Using Video Technology to Diagnose EFL Students Cognitive Learning Difficulties in Public Speaking. International Educational Technology Conference, Procedia- Social Behavioral Sciences, 64, 671- 680. Retrieved on December, 2014, from http://www.sciencedirect.com/science/article/pii/S1877042812050562

[19] Lin, Y. (2009). The effects of visual aids and text types on listening comprehension. Unpublished M.A., Taiwan Normal University. Retrieved from

http://www.google.com.sa/url?url=http://ir.lib.ntnu.edu.tw/retrieve/51153/metadata_02_02_s_05_0118.pdf\&rct=j\&frm=1\&q=\&esrc=s\&sa= U\&ei=xx8bVKL3AsiP7AbtjYDIAg\&ved=0CBQQFjAA\&usg=AFQjCNGITBal6-KUrBp3oV1wdVH79PQFNA

[20] Luo, J. (2004). Using DVD films to enhance college freshmen's English listening comprehension and motivation. Unpublished M.A., National Tsing Hua University, Taiwan. Retrieved from

http://www.google.com.sa/url?url=http://www.hss.nthu.edu.tw/ fl/thesis/tesol/905256.pdf\&rct=j\&frm=1\&q=\&esrc=s\&sa=U\&ei=NhlbVJO vL8bKOKL_gMgB\&ved=0CBIQFjAA\&usg=AFQjCNH8Ptlb7g1lfogsgSR-hzwE2qLg9w

[21] Prensky, M. (2001). Digital natives, digital immigrants. Digital Natives Digital Immigrants, 9(5), 1-6.

[22] Suvorov, R. (2008). Context visuals in 12 listening tests: The effectiveness of photographs and video vs. audio-only format. Unpublished M.A. thesis, lowa State University, USA.

[23] Stempleski, S. (1987, April). Short Takes: Using Authentic Video in the English Class. Paper Presented at the Annual Meeting of the International Associations of Teachers of English asa Foreign Language, 1-17. Belgium. ED 294453. Retrieved on December, 2014, from http://files.eric.ed.gov/fulltext/ED294453.pdf

[24] Shahani, S., Tahriri., \& Divsar. (2014, January). EFL Learners' Views towards Video Materials and Viewing Techniques. International SAMANM Journal of Business and Social Sciences,2 (1), 42-60. Retrieved on November, 2014, from http://www.samanmjournals.org/wpcontent/uploads/EFL-Learners-views-towards-video-materials.pdf

[25] Terantino, J. M. (2011, February). Emerging Technologies: YouTube for Foreign Languages. Language Learning and Technology, 15 (1), $10-$ 16. Retrieved on January, 2015, from http://lt.msu.edu/issues/february2011/emerging.pdf

[26] Yassaei, S. (2012). Using Original Videos and Sound Effects to Teach English. English Teaching Forum, (1), 12-16. UK. Retrieved on December, 2014, from http://americanenglish.state.gov/files/a/resourse files/50 14 yassai.pdf 